\title{
EXERGETIC OPTIMISATION OF A HEAT EXCHANGER
}

\section{R. L. CORNELISSEN and G. G. HIRS}

University of Twente, Dept of Mechanical Eng., Chair of Energy Technology, P.O. Box 217 , 7500 AE Enschede, The Netherlands

(Received 1 November 1996)

\begin{abstract}
The objective of this paper is to show that for the optimal design of an energy system, where there is a trade-off between exergy saving during operation and exergy use during construction of the energy system, exergy analysis and life cycle analysis should be combined. The two methods are often used separately, but a limited number of studies has been carried out in which they are combined in some way. An exergetic optimisation of a heat exchanger has been carried out on the basis of the life cycle analysis method in this paper. The optimisation takes into account irreversibilities due to frictional pressure drops and the temperature difference between the hot and cold stream and irreversibilities due to the production of the materials and the construction of the heat exchanger. As an example of this type of heat exchanger, a water to water heat exchanger in a city heating system has been selected. The influence of the configuration of the heating system, including the energy conversion, on the optimisation of the heat exchangers has been shown. The analysis of the heat exchanger in which exergy analysis and life cycle analysis are combined gives the design conditions of the heat exchangers which lead to the lowest life cycle irreversibility. (C) 1997 Elsevier Science Ltd
\end{abstract}

Heat exchangers Exergy analysis Life cycle analysis Thermodynamic optimisation

\section{NOMENCLATURE}

$A=$ Heat transfer area

$c_{\mathrm{p}}=$ Heat capacity

$C=$ Cumulative exergy destruction

$D=$ Inner diameter of the tube

$d=$ Thickness of the tube wall

$e=$ Effectiveness

$f(\mathrm{Re})=$ Friction factor

$I=$ Irreversibility or exergy destruction

$L=$ Length of the tubes

$M=$ Mass

$\dot{m}=$ Mass flow

$N u=$ Nusselt number

$N_{\mathrm{tu}}=$ Number of heat transfer units

$P=$ Pressure

$P r=$ Prandtl number

$R e=$ Reynolds' number

$T=$ Temperature

$T_{1}=$ Inner tube temperature

$T_{2}=$ Outer tube temperature

$u=$ Mean velocity of the fluid in the tube

$x=$ Recycling ratio of the material

Greek Letters

$\alpha=$ Heat transfer coefficient

$\rho=$ Density

$\lambda=$ Coefficient of thermal conduction

$\mu=$ Dynamic viscosity

Subscripts

$0=$ Environmental

$1=$ Inner tube of the heat exchanger

$2=$ Outer tube of the heat exchanger

$\mathrm{Cu}=$ Copper

$\mathrm{h}=$ Hydraulic

$\mathbf{S}=$ Steel

in $=$ Inlet

LC $=$ Life cycle

man $=$ Manufacturing 


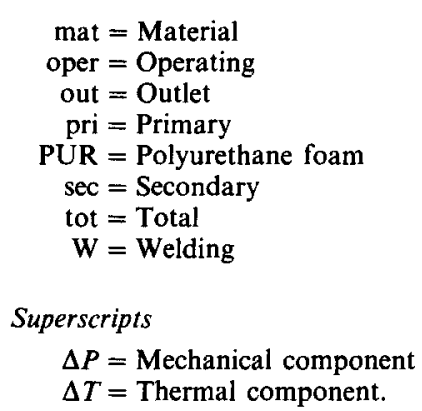

\section{INTRODUCTION}

Exergy analysis and life cycle analysis have been developed separately. Exergy analysis has been described extensively in the books of Kotas [1] and Szargut et al. [2]. Life cycle analysis (LCA) has been described by Moll [3] and Heijungs et al. [4]. The latter one gives a detailed methodology to use in a LCA. The methodology in the LCA includes the effects of all the phases of the production, use and recycling, on the environment. In this paper the methodology has been performed using only one criterion, which is the minimisation of the life cycle irreversibility associated with the delivery of domestic hot water. The complete LCA involves other factors e.g. pollution of air and water, noise etc., which were not considered here. The concept of cumulative exergy, introduced by Szargut, uses the method of accumulation of the exergy consumption to a defined point in the life cycle analysis [2]. The cumulative exergy consumption of a product takes into account all the exergy destruction for the manufacture of the product. However, in this method the exergy destruction associated with the disposal of the product and the influence of recycling which cause a change in the exergy destruction are not taken into account. Because of its widespread use the heat exchanger has been selected as an example.

Bejan [5] extensively studied the optimisation of a heat exchanger, excluding exergy destruction associated with the use of materials and cumulative exergy of generation of heat and power. His approach uses the concept of entropy generation minimisation. An extension to his approach, to include material use, has been made by Aceves-Saborio et al. [6]. They took into account the cumulative exergy of the material, but did not include the irreversibility due to the pressure drops.

Tondeur and Kvaalen [7] have shown that in the case of heat exchangers or separation devices involving a given heat transfer and achieving a specified transfer duty, the total entropy produced is minimal when the local rate of entropy production is uniformly distributed along space variables and time. De Oliveira et al. [8] has shown that in the case of an optimal heat exchanger, the thermal and viscous contributions to the entropy generation should be equal. It is shown that this is a good optimising technique when there are constraints on the amount of used material, like a fixed heat transfer area in the case of a heat exchanger. However, it is not shown that this can be applied when these constraints are lifted.

Lozano and Valero [9] have developed a theory to allocate monetary cost on the basis of exergy. In this method they define a matrix containing all irreversibilities, including irreversibilities associated with the building of installations and the disposal of waste materials.

\section{OPTIMISATION OF A HEAT EXCHANGER}

\section{(a) The heat exchanger}

The heat exchanger analysed is a balanced counter flow heat exchanger, which is used in a city heating system to heat the domestic tap water. The inner tube carries the cold stream and the surrounding, outer tube carries the hot stream. An equal mass flow of the hot and cold water has been assumed. The inner and outer tube have been constructed from copper and steel, respectively. The combined annular heat exchanger is helically wound as shown in Fig. 1. The influence of winding on the pressure drop has been neglected. The thermal insulation of the heat exchanger has been assumed to be perfect. 


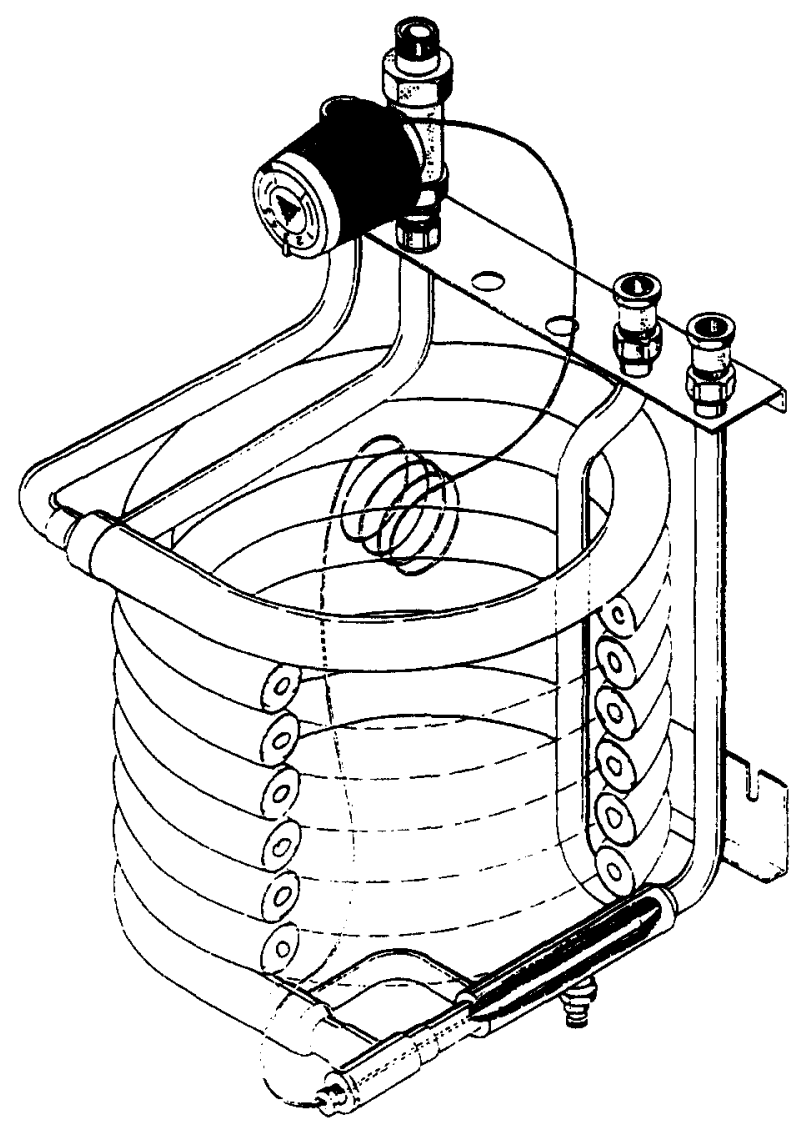

Fig. 1. The analysed heat exchanger.

\section{(b) Theory}

The following formula can be derived for the irreversibility in the heat exchanger due to the stream to stream heat transfer and pressure drops:

$$
\dot{I}=\dot{I}^{\Delta T}+\dot{I}^{\Delta P}
$$

with

$$
\dot{I}^{\Delta T}=T_{0}\left[\dot{m} c_{\mathrm{p}} \ln \frac{T_{1, \text { out }}}{T_{1, \text { in }}}+\dot{m} c_{\mathrm{p}} \ln \frac{T_{2, \text { out }}}{T_{2, \text { in }}}\right]
$$

and

$$
\dot{I}^{\Delta P}=\frac{\dot{m}}{\rho}\left(P_{1 \text {.in }}-P_{\text {l.out }}\right)+\frac{\dot{m}}{\rho}\left(P_{2 \text {.in }}-P_{2 \text {.out }}\right) .
$$

The heat exchanger effectiveness is:

$$
e=\frac{T_{1, \text { in }}-T_{1, \text { out }}}{T_{1, \text { in }}-T_{2, \text { in }}}=\frac{T_{2, \text { in }}-T_{2, \text { out }}}{T_{1, \text { in }}-T_{2, \text { in }}}
$$

In a nearly ideal heat exchanger limit $N_{\mathrm{tu}} \gg 1$ and, therefore, $1-e \approx 1 / N_{\mathrm{tu}}$, where $N_{\mathrm{tu}}=\alpha A / \dot{m} c_{\mathrm{p}}$. Neglecting the heat resistance of the tube wall we have according to Bejan [5]

$$
\dot{I}^{\Delta T}=T_{0}\left[\frac{\dot{m}^{2} c_{\mathrm{p}}^{2} \tau^{2}}{\alpha_{1} A}+\frac{\dot{m}^{2} c_{\mathrm{p}}^{2} \tau^{2}}{\alpha_{2} A}\right]=T_{0} \cdot \dot{m} c_{\mathrm{p}}\left[\frac{\tau^{2}}{N_{\mathrm{tu}, \mathrm{l}}}+\frac{\tau^{2}}{N_{\mathrm{tu}, 2}}\right]
$$


with

$$
\tau=\frac{\left|T_{2, \text { in }}-T_{1, \text { in }}\right|}{\sqrt{T_{1, \text { in }} T_{2, \text { in }}}} .
$$

By using the force balance inside the tube(s) we can write for the pressure drops:

$$
\begin{gathered}
\Delta P_{1}=P_{1, \text { in }}-P_{1, \text { out }}=2 f_{1}(R e) \cdot \rho \cdot \bar{u}_{1}^{2} \frac{L}{D_{1}} \\
\Delta P_{2}=P_{2, \text { in }}-P_{2, \text { out }}=2 f_{2}(R e) \cdot \rho \cdot \bar{u}_{2}^{2} \frac{L \cdot\left(D_{1}+2 d_{1}+D_{2}\right)}{\left(D_{2}^{2}-\left(D_{1}+2 d_{1}\right)^{2}\right)} .
\end{gathered}
$$

Using

$$
\bar{u}_{1}=\frac{4 \dot{m}}{\rho \pi D_{1}^{2}} \quad \text { and } \quad \bar{u}_{2}=\frac{4 \dot{m}}{\rho \pi\left[D_{2}^{2}-\left(D_{1}+2 d_{1}\right)^{2}\right]}
$$

and substituting equations $(4 \mathrm{a})$ and $(4 \mathrm{~b})$ in equation $(1 \mathrm{~b})$ yields

$$
\dot{I}^{\Delta P}=\frac{32}{\pi^{2}}\left[f_{1}(R e) \frac{\dot{m}^{3}}{\rho^{2}} \frac{L}{D_{1}^{5}}+f_{2}(R e) \frac{\dot{m}^{3}}{\rho^{2}} \frac{L \cdot\left(D_{1}+2 d_{1}+D_{2}\right)}{\left[D_{2}^{2}-\left(D_{1}+2 d_{1}\right)^{2}\right]^{3}}\right]
$$

or in the rewritten form

$$
\dot{I}^{\Delta P}=2 \pi \mu\left[f_{1}(\operatorname{Re}) \cdot \operatorname{Re} \bar{u}_{1}^{2} L+f_{2}(\operatorname{Re}) \cdot \operatorname{Re} \bar{u}_{2}^{2} \frac{L \cdot\left(D_{1}+2 d_{1}+D_{2}\right)}{D_{\mathrm{h}, 2}}\right]
$$

with $D_{\mathrm{h} .2}=D_{2}-D_{1}-2 d_{1}$.

In the turbulent flow region in tubes and annular spaces with a limited temperature difference of $5 \mathrm{~K}$ for liquids, between the bulk fluid and pipe surface temperature, we have according to Chapman [10]

$$
N u=\frac{\alpha D_{\mathrm{h}}}{\lambda}=0.023 \operatorname{Re}^{0.8} \operatorname{Pr}^{n}=0.023 \cdot\left(\frac{\rho \bar{u} D_{\mathrm{h}}}{\mu}\right)^{0.8} \cdot\left(\frac{c_{\mathrm{p}} \mu}{\lambda}\right)^{n}
$$

with $n=0.3$ or 0.4 for cooling or heating, respectively. Experimental data of Kays and London [11] gives a similar relation.

The friction factor in tubes according to the friction law of Blasius is given in Rogers and Mayhew [12] as

$$
f(R e)=\frac{0.0791}{R e^{0.25}}=0.0791 \cdot\left(\frac{\mu}{\rho \bar{u} D_{\mathrm{h}}}\right)^{0.25} .
$$

Substituting equations (6) and (7) in equation (5) and using $A \approx \pi \cdot L \cdot D_{1}$, we obtain

$$
\dot{I}^{\Delta T}=T_{0} \frac{14.3 \dot{m}^{1.2}}{\pi^{0.2}}\left[\frac{c_{p}^{1.6} \tau^{2} \mu^{0.4}}{\lambda^{0.6}} \frac{D_{1}^{0.8}}{L}+\frac{c_{\mathrm{p}}^{1.7} \tau^{2} \mu^{0.5}}{\lambda^{0.7}} \frac{\left(D_{2}+D_{1}+2 d_{1}\right)^{0.8} D_{\mathrm{h}, 2}}{L \cdot D_{1}}\right]
$$

with $D_{\mathrm{h}, 2}=D_{2}-D_{1}-2 d_{1}$ and

$$
\dot{I}^{\Delta P}=\frac{1.79}{\pi^{1.75}} \frac{\dot{m}^{2.75} \mu^{0.25}}{\rho^{2}}\left[\frac{L}{D_{1}^{4.75}}+\frac{L \cdot\left(D_{1}+2 d_{1}+D_{2}\right)^{1.25}}{\left[D_{2}^{2}-\left(D_{1}+2 d_{1}\right)^{2}\right]^{3}}\right] .
$$

\section{(c) Cumulative losses due to power and heat generation}

Irreversibilities in heat exchangers are associated with external exergy destruction, for example, to overcome the frictional losses in the heat exchanger, a pressure difference is needed. The generation of heat and power is associated with exergy destruction, which has to be taken into 


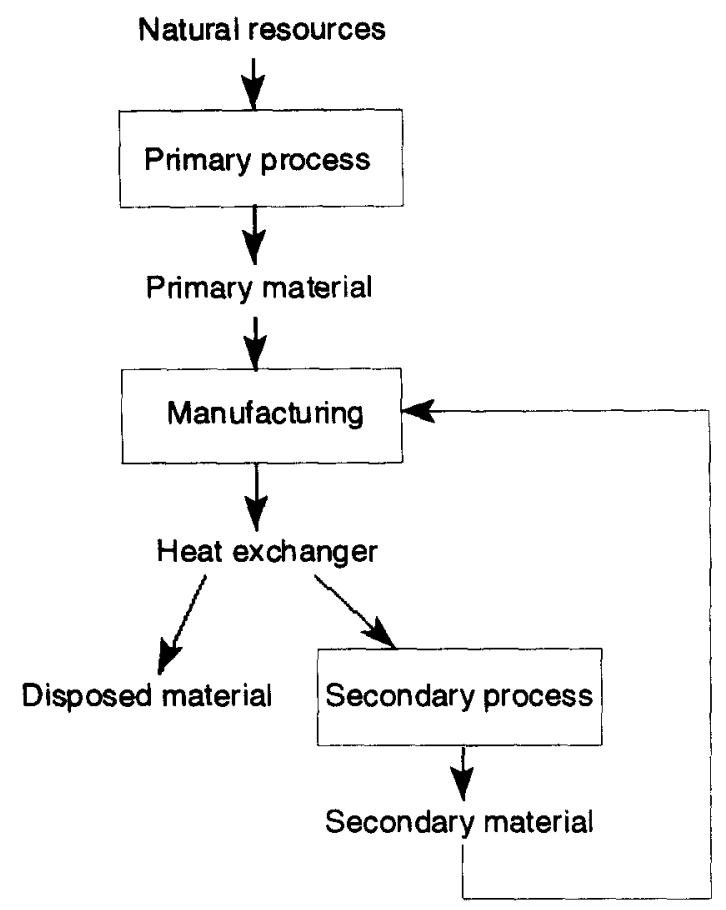

Fig. 2. Life cycle of the heat exchanger.

account in the optimisation, according to the LCA. We assume the following situation based on the city heating system in Enschede, The Netherlands. In this system a cogeneration heat and power plant, a steam and gas turbine plant (STAG), is used, which has an exergetic efficiency of $50 \%$, when there is no useful heat production. The exergetic efficiency of the extraction type of plant stays nearly constant when a part of the steam is used for the city heating system. Irreversibilities associated with the building of the combined heat and power plant and the transport of the fuel, natural gas, are neglected.

The exergetic efficiency of the heat transport to the houses is estimated to be 0.5 for a widespread distribution net* (wide net) and 0.75 for a very dense distribution net (dense net). The exergy destruction in the wide net is greater, because of more power needed to overcome the frictional pressure drops and more heat transfer to the environment. A great part of the exergy destruction in the heat transport takes place because of the temperature difference in the heat exchanger between the main transport tube and the local distribution net. It has been assumed that the exergy destruction associated with the heat transport is independent of the city heating water temperature. The exergetic efficiency of the pumps is assumed to be 0.7 .

Hence, the exergetic cost for the analysed heat exchanger of pressure rise, $k_{\mathrm{p}}$, and heat, $k_{\mathrm{T}}$, can be calculated to be 2.85 and 4 for the wide net and 2.85 and 2.66 for the dense net, respectively. The exergetic cost of a product is the amount of exergy which is needed for the production of one exergy unit of the product.

For the exergy destruction associated with the operation of the heat exchangers we have

$$
\dot{I}_{\text {oper }}=k_{\mathrm{T}} \dot{I}^{\Delta T}+k_{\mathrm{P}} \dot{I}^{\Delta P} \text {. }
$$

(d) Irreversibilities associated with the use of the material

The life cycle flow diagram of the heat exchanger is displayed in Fig. 2. The exergy destruction in each process is shown in Table 1.

A detailed exergy analysis of the primary anode copper process is presented by Kolenda et al. [13]. The cumulative irreversibility of the flash smelting process, one of the main copper

*This is a hypothetical situation. In reality the exergy losses are higher because the peak in heat demand is supplied by auxiliary heating boilers using natural gas. Their exergetic efficiency is very poor. 
Table 1. Exergy destruction associated with the production of material and manufacturing of tubes

\begin{tabular}{lcc}
\hline Process & $I_{\mathrm{s}}(\mathrm{MJ} / \mathrm{kg})$ & $I_{\mathrm{Cu}}(\mathrm{MJ} / \mathrm{kg})$ \\
\hline Primary process & 10.5 & 60 \\
Secondary process & 4.4 & 20 \\
Manufacturing process & 5.7 & 15 \\
\hline
\end{tabular}

production processes, is shown to be $45.8 \mathrm{MJ} / \mathrm{kg}$ anode copper. However, the exergy destruction consists of the exergy dissipation in the process and the exergy of materials, which are assumed to be discharged and dissipated into the environment, like slag and combustion gases. So the total cumulative exergy destruction is $55.6 \mathrm{MJ}$ per $\mathrm{kg}$ primary anode copper.

No recent publication about the exergy destruction of the production of primary steel, the production of copper out of anode copper, the production of secondary copper and manufacturing of steel and copper tubes is available so, instead of the exergy destruction, the energy consumption has been taken. To use the energy consumption instead of the exergy destruction, due to lack of sufficient data, the following conditions have to be fulfilled. Most inputs ought to be raw materials, because the exergy and enthalpy content are then roughly equal. The exergy increase of the product during the processing has to be subtracted from the energy use to get the exergy destruction.

The cumulative energy use of the production of solid copper out of anode copper is around $4.5 \mathrm{MJ} / \mathrm{kg}$ copper according to Boustead and Hancock [14]. The exergy increase is almost zero and we assume the enthalpy values of the inputs to be equal to the exergy values, so this value is taken for the exergy destruction. The cumulative exergy destruction for primary copper becomes $55.6+4.5=60.1 \mathrm{MJ} / \mathrm{kg}\left(C_{\text {pri.Cu }}\right)$.

The energy use for the production of primary steel slabs is $16.9 \mathrm{MJ} / \mathrm{kg}^{*}$ according to Worrell et al. [15]. Because most inputs are raw materials of which the exergy content roughly equals the energy content the cumulative exergy use is estimated to be equal to the energy use. The exergy destruction is the exergy input reduced by the exergy increase from the iron oxide to the steel. The exergy increase is estimated to be $6.4 \mathrm{MJ} / \mathrm{kg}$, so the exergy destruction is $10.5 \mathrm{MJ} / \mathrm{kg}\left(C_{\text {pris.s }}\right)$. The cumulative exergy destruction of secondary steel is calculated from Wall [16] by assuming the efficiency of the electricity production to be 0.5 . The exergy destruction associated with the production of the alloying materials and lime has been neglected. Boustead and Hancock [14] give two totally different values for the energy consumption of the secondary copper production, namely 7.2 and $48.8 \mathrm{MJ} / \mathrm{kg}$. The exergy destruction of this process is taken to be $20 \mathrm{MJ} / \mathrm{kg}\left(C_{\text {see.Cu }}\right)$. The manufacturing process of the steel tubes includes hot and cold rolling and the bending of the tube. The energy consumption of hot and cold rolling is $5.3 \mathrm{MJ} / \mathrm{kg}$, according to Worrell [15]. The exergy destruction is assumed to be equal to the energy consumption, because the exergy of the material is hardly changed. The exergy destruction of the bending of steel has been estimated, by assuming that the metal is heated to $900^{\circ} \mathrm{C}$ by a gas heater. The exergy destruction associated with the force required to bend the steel has been neglected. The exergy destruction associated with the welding of steel tubes has been estimated to be $0.260 \mathrm{MJ}$ per meter $\left(C_{\mathrm{w}, \mathrm{S}}\right)$ according to the Dutch steel maker, Hoogovens IJmuiden. The energy consumption associated with the manufacturing of the copper tubes, which includes the welding of copper tubes, is $14.7 \mathrm{MJ} / \mathrm{kg}\left(C_{\text {man.Cu }}\right)$ according to Alvarado-Grandi [17]. The exergy destruction is assumed to equal the energy consumption, because the exergy of the material is hardly changed during the manufacturing.

The heat exchanger is located in an insulated box made of polyurethane foam (PUR) with a thickness of $0.10 \mathrm{~m}$. The cumulative energy consumption for the production of PUR with a density of $30 \mathrm{~kg} / \mathrm{m}^{3}$ is $98 \mathrm{MJ} / \mathrm{kg}$, according to Kindler et al. [18]. The exergy content is estimated to be $27 \mathrm{MJ} / \mathrm{kg}$ on the basis of the lower heating value according to Kindler $e t$ al. [18]. So the cumulative exergy destruction is $71 \mathrm{MJ} / \mathrm{kg}\left(C_{\mathrm{PUR}}\right)$. The box containing the heat exchanger has two outer sides of $0.70 \mathrm{~m}$. The height of the box is calculated from the length of the heat exchanger. The heat exchanger has been helically wound in three coaxial tubular layers. The mean diameter of the tube windings is $0.45 \mathrm{~m}$. No recycling of the PUR has been assumed.

*The energy use is based on the steel factory of Hoogovens IJmuiden in the Netherlands, which can be considered to be one of the most energy efficient steel factories in the world. 
The exergy destruction associated with the manufacture of the heat exchangers is due to the production of copper tube and steel tube, welding and the production of the PUR-foam box.

$$
\begin{aligned}
\dot{I}_{\mathrm{man}}= & \frac{M_{\mathrm{Cu}} C_{\mathrm{Cu}}+M_{\mathrm{fe}} C_{\mathrm{S}}+L C_{\mathrm{w}, \mathrm{S}}+M_{\mathrm{PUR}} C_{\mathrm{PUR}}}{t} \\
= & \frac{\pi L}{t}\left[\left(D_{1}+0.5 d_{1}\right) d_{1} \rho_{\mathrm{Cu}}\left(C_{\mathrm{man.C \textrm {Cu }}}+x_{\mathrm{Cu}} C_{\mathrm{sec}, \mathrm{Cu}}+\left(1-x_{\mathrm{Cu}}\right) C_{\mathrm{pr}, \mathrm{Cu}}\right)\right] \\
& +\frac{\pi L}{t}\left[\left(D_{2}+0.5 d_{2}\right) d_{2} \rho_{\mathrm{s}}\left(C_{\mathrm{man}, \mathrm{S}}+x_{\mathrm{S}} C_{\mathrm{sec}, \mathrm{S}}+\left(1-x_{\mathrm{S}}\right) C_{\mathrm{pri}, \mathrm{S}}\right)+C_{\mathrm{w}, \mathrm{S}}\right] \\
& +\frac{1}{t}\left[\left(4 \cdot \frac{L \cdot(0.7-0.1)}{3 \cdot \pi \cdot 0.45} \cdot\left(D_{2}+2 \cdot d_{2}\right)+2 \cdot 0.49\right) \cdot 0.10 \rho_{\mathrm{PUR}} C_{\mathrm{PUR}}\right]
\end{aligned}
$$

in which $t$ is the operating time of the heat exchanger during its life cycle and $x$ is the recycling ratio which is the proportion of secondary material, i.e. material which is recycled.

\section{RESULTS}

From the above considerations we obtain an expression for the total life cycle irreversibility, which has to be minimised.

$$
\dot{I}_{\mathrm{LC}}=\dot{I}_{\mathrm{oper}}-\dot{I}_{\mathrm{man}}
$$

where $\dot{I}_{\text {oper }}$ and $\dot{I}_{\text {man }}$ are stated in equations (9) and (10), respectively.

The following operating parameters have been assumed for the heat exchanger. The incoming temperature of the cold domestic tap water is $15^{\circ} \mathrm{C}$. The domestic tap water is heated to $65^{\circ} \mathrm{C}$. The temperature of the incoming city heating water is variable. The environmental temperature, $T_{0}$, is $25^{\circ} \mathrm{C}$. The operating time for the heat exchanger is $30 \mathrm{~min}$ a day on full load for $10 \mathrm{yr}$. The mass flow of the city heat water as the domestic water is $0.1 \mathrm{~kg} / \mathrm{s}$. The mean temperature of the inlet and outlet streams is used for the heat capacity, viscosity* and thermal conductivity of water. The wall thickness of the inner and outer tube are 0.8 and $2 \mathrm{~mm}$, respectively. The recycling ratio is set to be 0.9 for the copper and steel parts of the tube.

\section{(a) Reference configuration}

As a reference situation a domestic water heat exchanger is taken with the hypothetical fixed length of $30 \mathrm{~m}$. The optimised inner and outer tube diameters are $8.56 \times 10^{-3} \mathrm{~m}$ and $1.29 \times 10^{-2} \mathrm{~m}$ for the wide net and $9.04 \times 10^{-3} \mathrm{~m}$ and $1.36 \times 10^{-2} \mathrm{~m}$ for the dense net. The life cycle irreversibility of the heat exchanger in full operation is $1.82 \times 10^{3} \mathrm{~W}$ for the wide net and $1.34 \times 10^{3} \mathrm{~W}$ for the dense net. Resulting from a $\Delta T, \Delta P_{1}$ and $\Delta P_{2}$ of $5.24 \mathrm{~K}, 1.34$ bar and 7.57 bar for the wide net and $5.57 \mathrm{~K}, 1.03$ and 5.48 bar for the dense net, respectively. $\Delta T$ is the temperature difference between the hot and cold stream, which is constant because we have a balanced counter flow heat exchanger. $T_{1 . \text { out }}$, which can be calculated by $T_{2 . \text { in }}-\Delta T$, is set to $65^{\circ} \mathrm{C}$ by use of iterative calculations.

\section{(b) Results of optimisation}

The minimisation of $\dot{I}_{\mathrm{LC}}$ for the three variables, $D_{1}, D_{2}$ and $L$ gives the minimum value of life cycle irreversibility per heat exchanger in the wide net of the city heating system of $1.06 \times 10^{3} \mathrm{~W}$. The optimum geometrical parameters were found to be $D_{1}=1.07 \times 10^{-2} \mathrm{~m}, D_{2}=1.69 \times 10^{-2} \mathrm{~m}$ and $L=105.8 \mathrm{~m}$. The $\Delta T, \Delta P_{1}$ and $\Delta P_{2}$ of this optimised heat exchanger are $1.95 \mathrm{~K}, 1.62$ and 3.65 bar, respectively.

The dense net life cycle irreversibility is $8.76 \times 10^{2} \mathrm{~W}$ for $D_{1}=1.07 \times 10^{-2} \mathrm{~m}$, $D_{2}=1.69 \times 10^{-2} \mathrm{~m}$ and $L=87.0 \mathrm{~m}$. The $\Delta T, \Delta P_{1}$ and $\Delta P_{2}$ of the optimised heat echanger are $2.93 \mathrm{~K}, 1.34$ and $3.0 \mathrm{bar}$, respectively.

\footnotetext{
*The value of the viscosity is strongly temperature dependent. The viscosity at $15^{\circ} \mathrm{C}, 70^{\circ} \mathrm{C}$ and $80^{\circ} \mathrm{C}$ is $1.14 \cdot 10^{-3} \mathrm{~Pa} \cdot \mathrm{s}$, $0.406 \cdot 10^{-3} \mathrm{~Pa} \cdot \mathrm{s}$ and $0.357 \cdot 10^{-3}$, respectively. So the assumption of the mean temperature will cause a deviation from the real situation.
} 
Table 2. Components of life cycle irreversibility in watts

\begin{tabular}{lcccc}
\hline Component & $\begin{array}{c}\text { Wide net } \\
(L=30 \mathrm{~m})\end{array}$ & $\begin{array}{c}\text { Dense net } \\
(L=30 \mathrm{~m})\end{array}$ & Wide net & Dense net \\
\hline Thermal & 1451 & 1033 & 514 & 422 \\
Mechanical & 255 & 186 & 151 & 124 \\
Manufacture & 114 & 118 & 395 & 330 \\
Total & 1820 & 1337 & 1060 & 876 \\
\hline
\end{tabular}

We see that for optimal geometrical parameters the tube diameters are independent of the efficiency of the distribution net, the dense or wide net. However, the length of the tube is strongly dependent on the type of distribution net. The components of the life cycle irreversibility in the heat exchanger are displayed in Table 2.

The contribution of the use of copper, steel and PUR-foam to the irreversibility associated with the manufacture is 39,42 and $19 \%$ for the wide and dense net optimisation and 32,33 and $35 \%$ for the both heat exchangers with a length of $30 \mathrm{~m}$, respectively.

\section{(c) Discussion}

The effect of the tube diameters and the length on life cycle irreversibility for the optimal geometrical parameters is shown in Fig. 3. The cross-sections of flow areas of the inner and outer passages are set fixed in the ratio of 1:0.863 to get a three-dimensional figure. This ratio has been obtained for the optimisation of the wide net. In Fig. 3 can be seen that the life cycle irreversibility rate rises for smaller tube length and inner tube diameter. At zero length or at zero tube diameter, the life cycle irreversibility rate becomes, of course, infinite. The effects of the diameters and the length on $I_{\mathrm{LC}}$ is greatest at their smallest values. The optimal inner tube diameter varies from around $0.8 \times 10^{-2} \mathrm{~m}$ for smaller lengths to $1.1 \times 10^{-2} \mathrm{~m}$ for longer lengths of the tube.

An increase of the operating time of the heat exchanger leads to optimal geometrical parameters with greater diameters and a longer heat exchanger as shown in Tables 3 and 4 . It can be seen that an increase of the operating time leads to a relatively small increase of the tube diameters $D_{1}$, $D_{2}$ and a greater increase of the length. The life cycle irreversibility rate decreases steadily by an increase of the operating time. There are no significant differences between the wide and dense net for the relation operating time and optimal geometrical parameters.

The analysis carried out in this work is only applicable to the situation when both the heat and the power are supplied from a cogeneration plant. If the heat is provided by a source which produces only heat from combustion of fossil fuel, the exergy saved in the heat exchanger will be

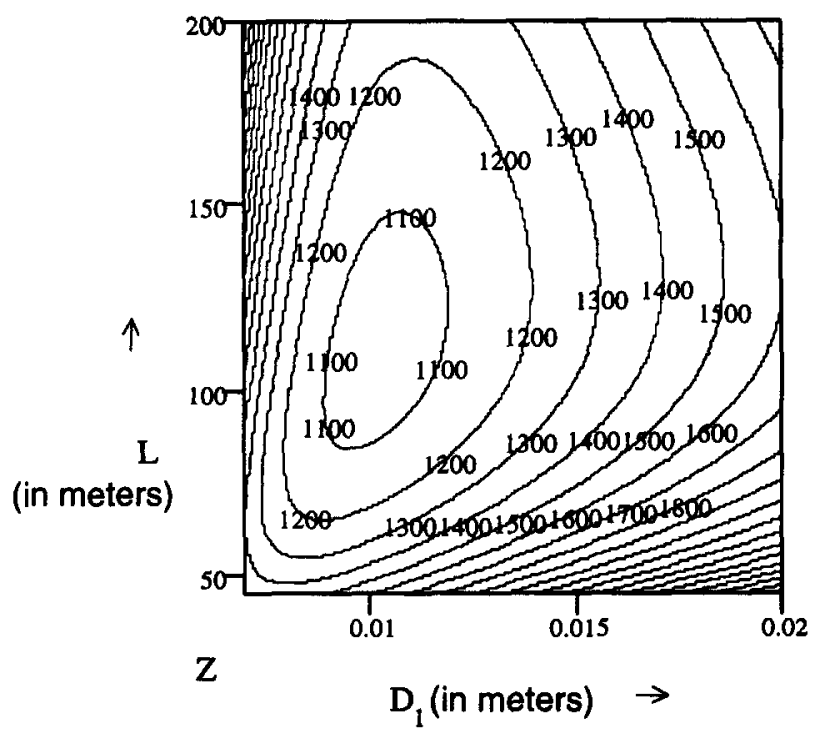

Fig. 3. Life-cycle irreversibility (in Watts) against length and diameter of the heat exchanger. 


\begin{tabular}{|c|c|c|c|c|}
\hline $\begin{array}{l}t \\
\text { (years) }\end{array}$ & $\begin{array}{c}\dot{L}_{\mathrm{LC}} \\
(\mathrm{kW})\end{array}$ & $\begin{array}{c}D_{1} \\
\left(10^{-2} \mathrm{~m}\right)\end{array}$ & $\begin{array}{c}D_{2} \\
\left(10^{--2} \mathrm{~m}\right)\end{array}$ & $\begin{array}{c}L \\
(\mathrm{~m})\end{array}$ \\
\hline 5 & 1.39 & 0.95 & 1.51 & 75.9 \\
\hline 10 & 1.06 & 1.07 & 1.69 & 105.8 \\
\hline 15 & 0.91 & 1.15 & 1.80 & 128.5 \\
\hline 20 & 0.82 & 1.21 & 1.89 & 147.8 \\
\hline
\end{tabular}

\begin{tabular}{lcccc} 
Table & $\begin{array}{l}\text { 4. Optimal } \\
\text { irreversibility for the dense }\end{array}$ & \multicolumn{2}{c}{ peomet for different times } \\
\hline$t$ & $\begin{array}{c}I_{\mathrm{LC}} \\
(\mathrm{kW})\end{array}$ & $\begin{array}{c}D_{1} \\
\left(10^{-2} \mathrm{~m}\right)\end{array}$ & $\begin{array}{c}D_{2} \\
\left(10^{-2} \mathrm{~m}\right)\end{array}$ & $\begin{array}{c}L \\
(\mathrm{~m})\end{array}$ \\
\hline years) & 1.16 & 0.95 & 1.51 & 62.5 \\
\hline 5 & 0.88 & 1.07 & 1.69 & 87.0 \\
10 & 0.75 & 1.15 & 1.80 & 105.6 \\
15 & 1.21 & 1.89 & 121.3 \\
20 & 0.67 & 1.21 & \\
\hline
\end{tabular}

lost in the heater. There is no similar trade-off between exergy saving during operation and exergy use during construction of the heat exchanger, as is the case when heat and power are generated together. The saving in exergy, resulting from the use of a longer heat exchanger requiring lower heating water temperature, cannot, in this case, be utilised elsewhere, e.g. for generating more electricity.

It is possible that a heat exchanger with more than one heated water tube, arranged in parallel inside the larger, outer tube carrying the heating, may lead to a more efficient heat exchanger process. However, this matter must be left for further investigation.

The Reynolds numbers of the inner and outer flow are $19.8 \times 10^{3}$ and $7.15 \times 10^{3}$ for the optimal configuration of the heat exchanger, respectively, when the mean temperature of the inlet and outlet streams is taken for the viscosity of the water. For the fixed length optimisation the Reynolds numbers are between $7.72 \times 10^{3}$ and $24.4 \times 10^{3}$ for the inner and outer flow, so the condition for the turbulent flow region is fulfilled.

Heat transfer inside the heat exchanger box, which leads to exergy destruction, is neglected. If this is taken into account an insulation directly wound around the tubes would probably be more effective than the assumed box. However, if this is the case the analysis shown would not change drastically, because the exergy use during construction would still increase when the tubes become longer.

No heat transfer from the heat exchanger to the environment has been assumed. For the longest optimal heat exchanger the heat transfer to the environment is calculated to be $2.9 \%$ of the total amount of heat exchanged, when for the heat exchanger box an outside and a mean inside temperature of 20 and $45^{\circ} \mathrm{C}$ are assumed, respectively. The coefficient of thermal conduction is $0.024 \mathrm{~W} /(\mathrm{m} \cdot \mathrm{K})$ for the PUR. So the neglect of the heat transfer from the heat exchanger box to the environment is justified. The life cycle irreversibility associated with the material use could be reduced by changing the construction material of the heat exchanger box to a material with a lower exergy content, e.g. cork. The heat transfer to environment would only increase four times as the PUR is replaced by cork of the same thickness, which is still small.

The function to determine the irreversibility uses the nearly ideal heat exchanger limit. The log-function has been substituted by a linear relation. This introduces an error which is the smallest when $\Delta T$ is the smallest. In the optimised situation, $\Delta T=1.95 \mathrm{~K}$ and the error introduced because of this substitution is $0.7 \%$. When the $\Delta T$ increases to $5.57 \mathrm{~K}$ which is the case when $L=30 \mathrm{~m}$ the error becomes $1.8 \%$. However, to describe the life cycle irreversibility for all values of the variables, formulas have to be derived where this substitution does not take place.

\section{CONCLUSIONS}

With the combination of exergy analysis and life cycle analysis the optimal design of a heat exchanger can be obtained. For all energy systems where there is a trade-off between exergy saving 
during operation and exergy use during construction of the energy system this method should be adopted to get the true optimum from the point of view of conservation of exergy of natural resources.

In the case under study the optimal design parameters of the heat exchangers are obtained under the specified conditions. The dense net, which is a more energy efficient heat supply system than the wide net, has the same inner tubes diameters as the wide net, whilst the length of the heat exchanger is smaller for the former than for the latter. The dense net has lower life cycle irreversibility due to the manufacture of the heat exchanger compared to the wide net, because less exergy is saved by the same increase of exergy use due to the manufacture. The increase of the operating time leads to a slight increase in the inner tubes diameters and a greater increase in the length of the heat exchanger. In the optimised situation the life cycle irreversibility is more uniformly distributed between the component irreversibilities than in the fixed length of $30 \mathrm{~m}$ situation.

In general, we can conclude that the thermodynamic optimisation of the design parameters of a subsystem is dependent on the thermodynamic efficiency of the whole system and that the different components of the life cycle irreversibility of heat exchangers are more uniformly distributed when there are less restrictions on the design parameters for the optimisation.

Acknowledgement-We would like to thank Dr T. J. Kotas of Queen Mary and Westfield College, University of London, U.K., for his help and advice on this paper.

\section{REFERENCES}

1. Kotas, T. J., The Exergy Method of Thermal Plant Analysis. Krieger, Melbourne, FL, 1995.

2. Szargat, J., Morris, D. R. and Steward, F. R., Exergy Analysis of Thermal, Chemical and Metallurgical Processes. Hemisphere, New York, 1988.

3. Moll, H. C., Energy counts and materials matter in models for sustainable development. Ph.D. thesis, University of Groningen, The Netherlands, 1993.

4. Heijungs, R. et al., Environmental Life Cycle Analysis of Products. Center for environmental studies, University of Leiden, The Netherlands, 1992.

5. Bejan, A., Entropy Generation Through Heat and Flow. Wiley, New York, 1982.

6. Aceves-Saborio, S., Ranasinghe, J. and Reistad, G. M., ASME Journal of Heat Transfer, 1989, 111, $29-36$.

7. Tondeur, D. and Kvaalen, E., Industrial \& Engineering Chemistry Research, 1987, 26, 50-56.

8. De Oliveira, S., Schwarzer, B., Le Goff, P. and Tondeur, D., International Chemical Engineering, 1994, 34, 3.

9. Lozano, M. A. and Valero, A., Energy, 1993, 18, 9.

10. Chapman, A. J., Heat Transfer. Macmillan, New York, 1974.

11. Kays, W. M. and London, A. L., Compact Heat Exchangers, 3rd edn. McGraw-Hill, New York, 1984.

12. Rogers, G. F. C. and Mayhew, Y. R., Engineering Thermodynamics, Work and Heat Transfer. Longmans, London, 1967.

13. Kolenda, Z. et al., An Analysis of Cumulative Energy and Exergy Consumption in Copper Production. In ECOS'92, ed. A. Valero et al. Zaragoza, Spain, 1992, pp. 275-282.

14. Boustead, I. and Hancock, G. F., Handbook of Industrial Energy Analysis. Wiley, New York, 1979.

15. Worrell, E., Beer, de J. and Blok, K., In Energy Efficiency in Process Technology, ed. P. A. Pilavachi. Elsevier, Oxford, 1992, pp. 91-100.

16. Wall, G., Exergy - a useful concept. Ph.D. thesis, Chalmers University of Technology, Göteborg, Sweden, 1986.

17. Alvarado-Grandi, S. and Iribarne, J., Energy Consumption in the Primary Production of Copper, 14th World Energy Conference, Montreal, 1989

18. Kindler, H. and Nikles, A., Kunststoffe, 1980, 70, 12.

19. Worrell, E., Potentials for improved use of industrial energy and materials. Ph.D. thesis, University of Utrecht, The Netherlands, 1994. 